\title{
Lithium Metal Electrode Understanding Its Unique Characteristics and Functions
}

Boryann Liaw, Eric J Dufek, Gorakh M Pawar

March 2020

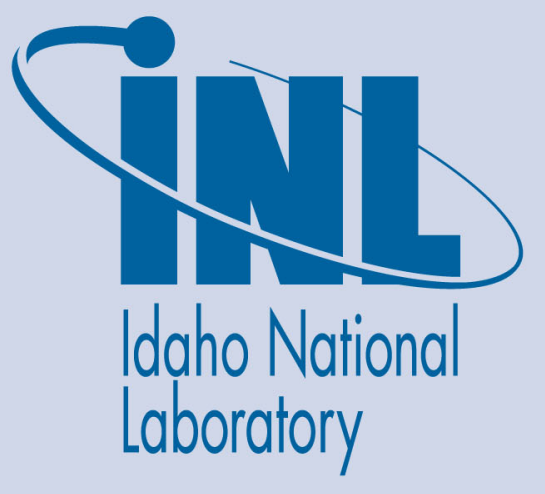

The INL is a U.S. Department of Energy National Laboratory operated by Battelle Energy Alliance 


\title{
Lithium Metal Electrode Understanding Its Unique Characteristics and Functions
}

\author{
Boryann Liaw, Eric J Dufek, Gorakh M Pawar
}

March 2020

Idaho National Laboratory Idaho Falls, Idaho 83415

http://www.inl.gov

Prepared for the U.S. Department of Energy

Office of Energy Efficiency and Renewable Energy Under DOE Idaho Operations Office

Contract DE-AC07-05ID14517 


\section{Lithium Metal Electrode - Understanding Its Unique Characteristics and Functions}

Gorakh Pawar, Yulun Zhang, Qiang Wang, Eric J. Dufek, Boryann Liaw*

Energy and Environmental Science and Technology Idaho National Laboratory

Idaho Falls, ID 83415, USA

Xuefeng Wang, Yejing Li, Minghao Zhang, Bingyu Lu, Abhik

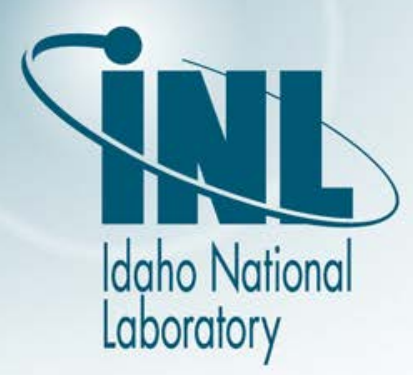
Banerjee, Ying Shirley Meng*

Department of NanoEngineering University of California San Diego La Jolla, CA 92093, USA 


\section{Congratulations}

\section{The Nobel Prize in Chemistry 2019}

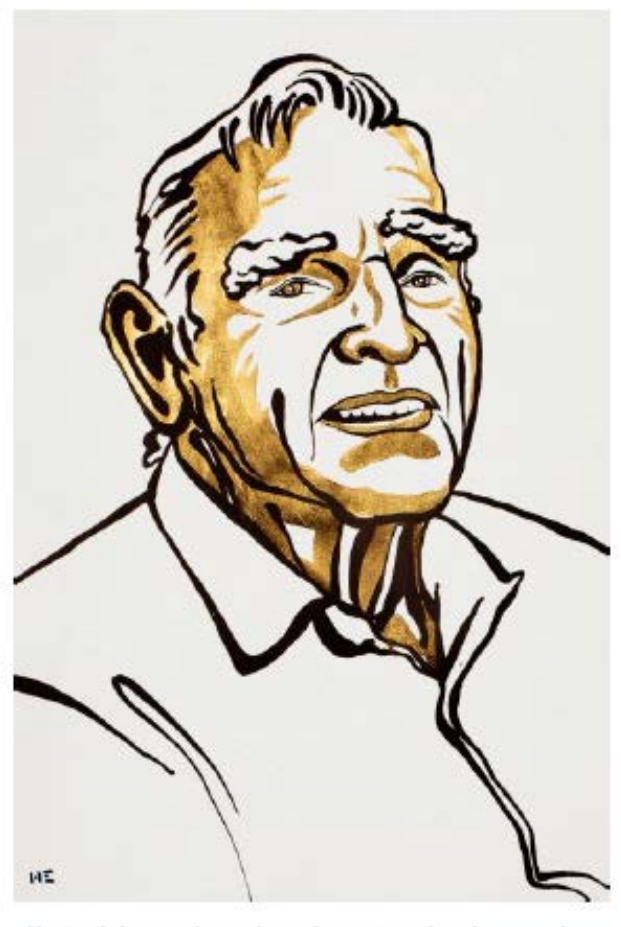

III. Niklas Elmehed. (c) Nobel Media. John B. Goodenough

Prize share: $1 / 3$

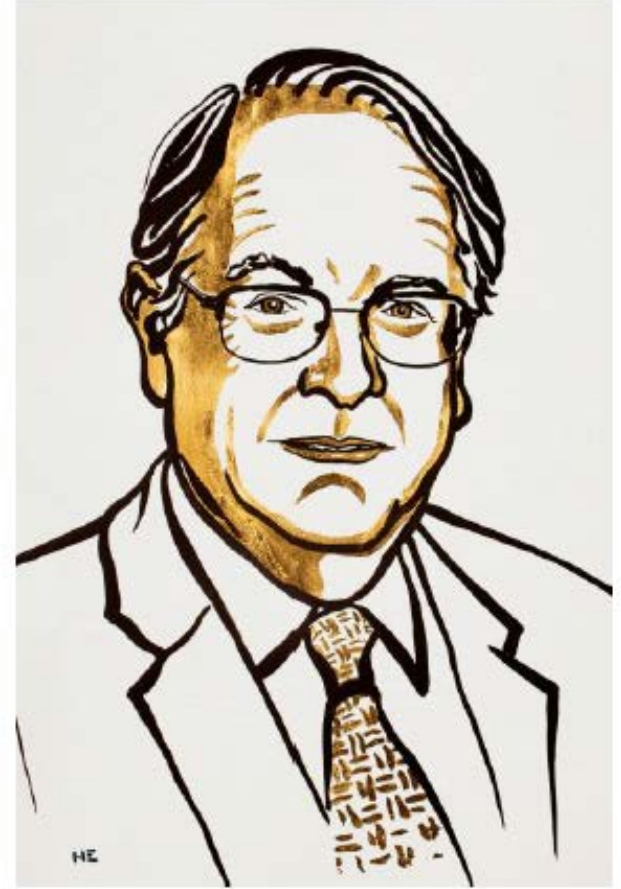

III. Niklas Elmehed. (c) Nobel Media. M. Stanley Whittingham

Prize share: $1 / 3$

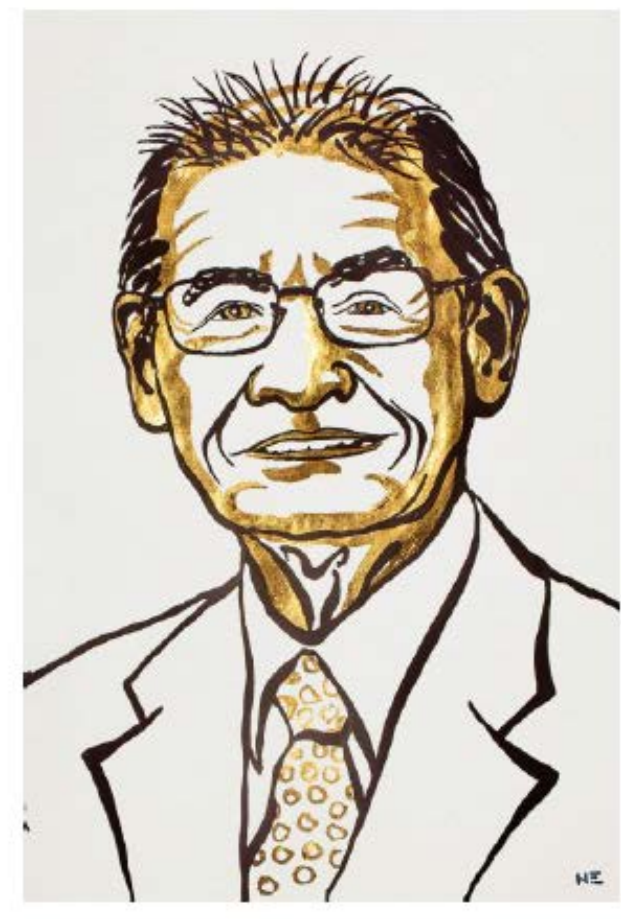

III. Niklas Elmehed. @ Nobel Media. Akira Yoshino

Prize share: $1 / 3$ 


\section{Remember the Pioneers}

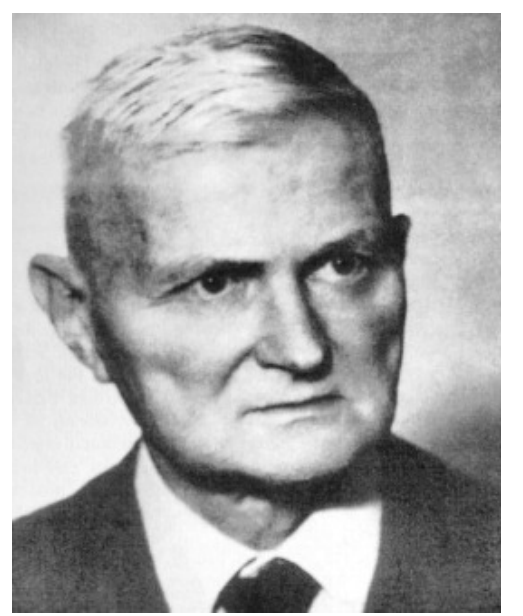

Carl Wagner in 1970's

https://www.ncbi.nlm.nih.gov/pmc/articles/PMC5090311/

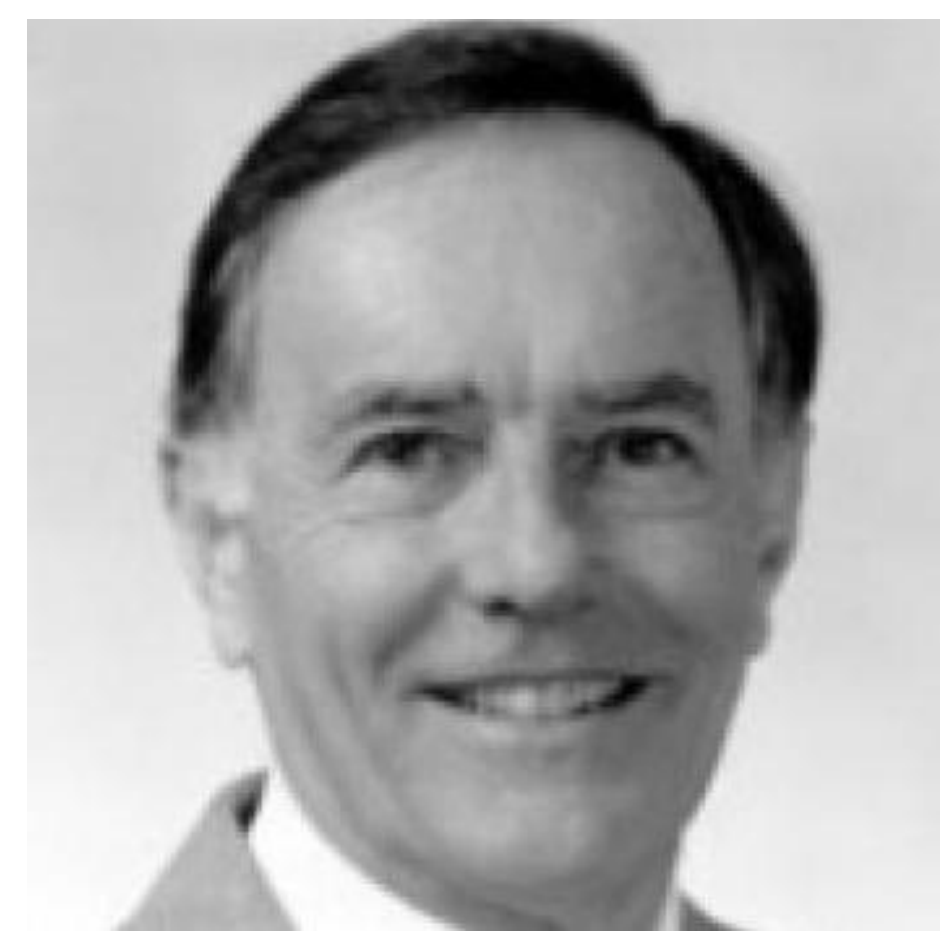

Bob in 1980's

https://profiles.stanford.edu/robert-huggins and, many others... 


\section{Make the Rechargeable Li Battery Great Again}

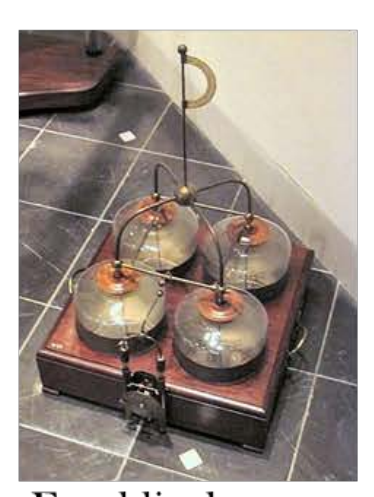

Franklin battery

1749

(capacitor)
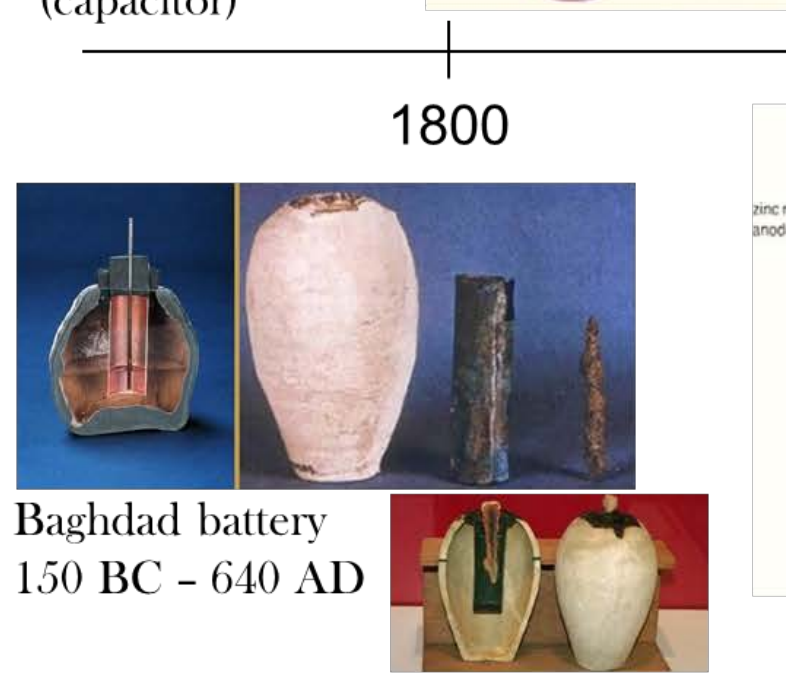

Planté lead-acid
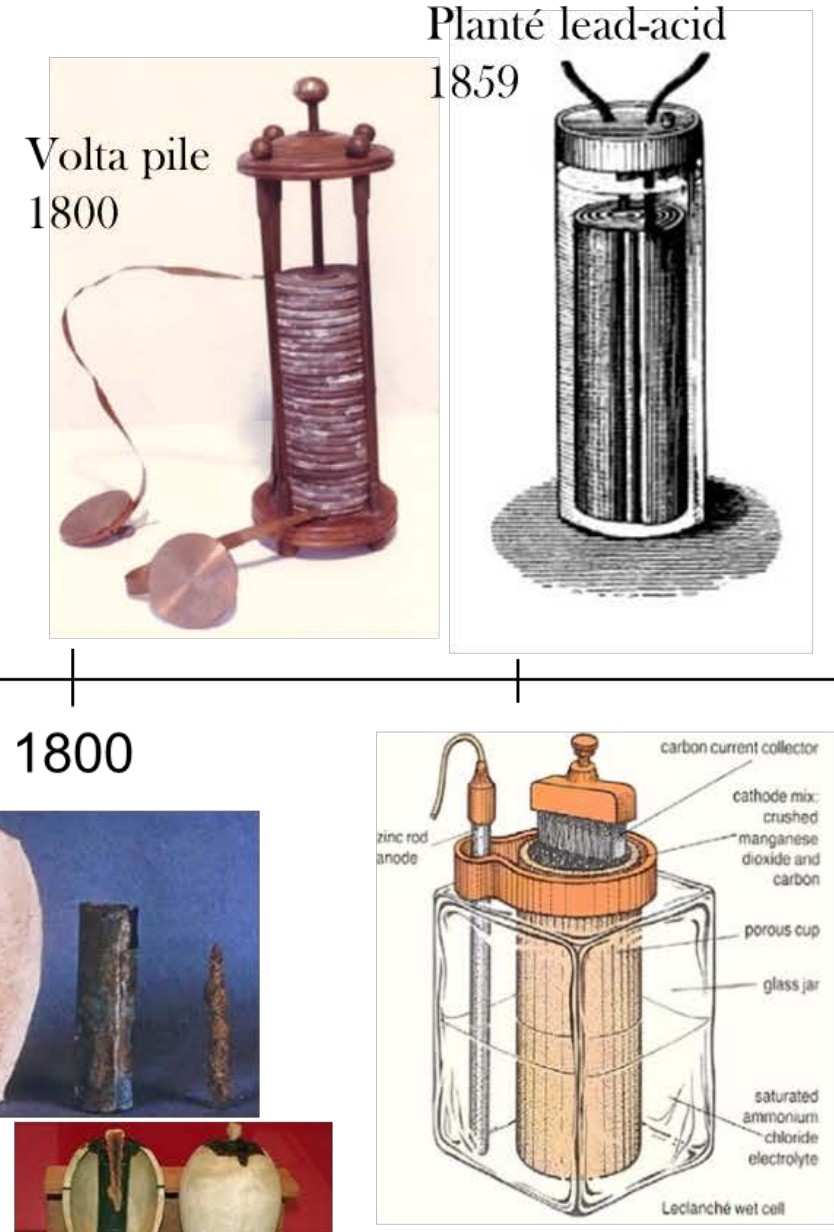

Leclanché cell 1866
Matsushita's Li

primary cell

1972

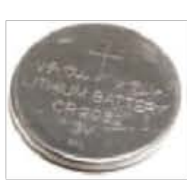

Moser's solid

Li-I cell

1972
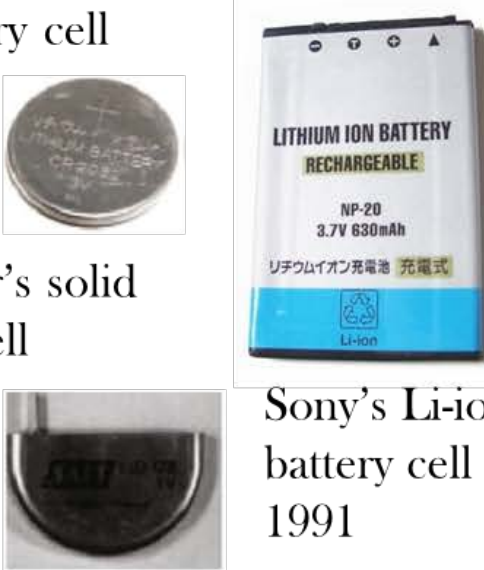

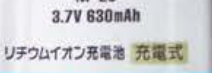

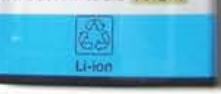

Sony's Li-ion

battery cell

1991

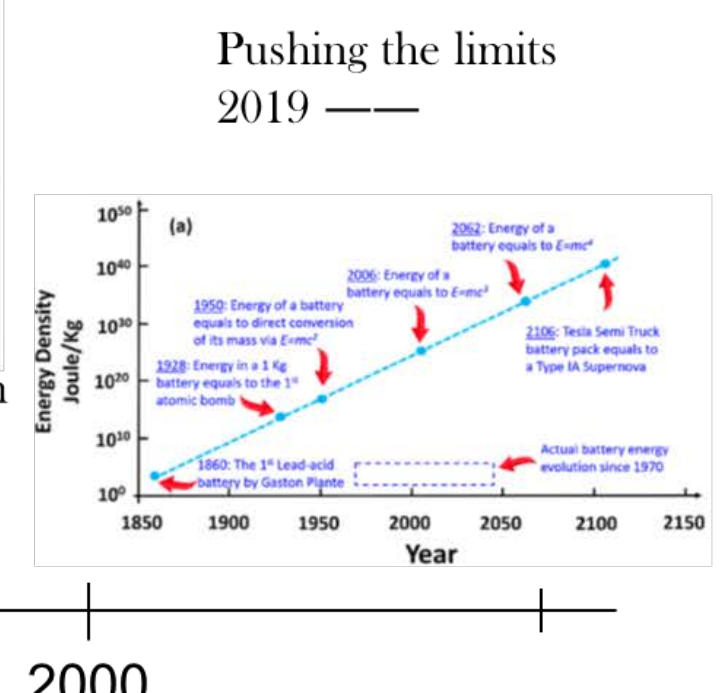

Whittingham's

organic rechargeable

Li battery (RLB)

1977

Armand's polymer

electrolyte RLB 1978

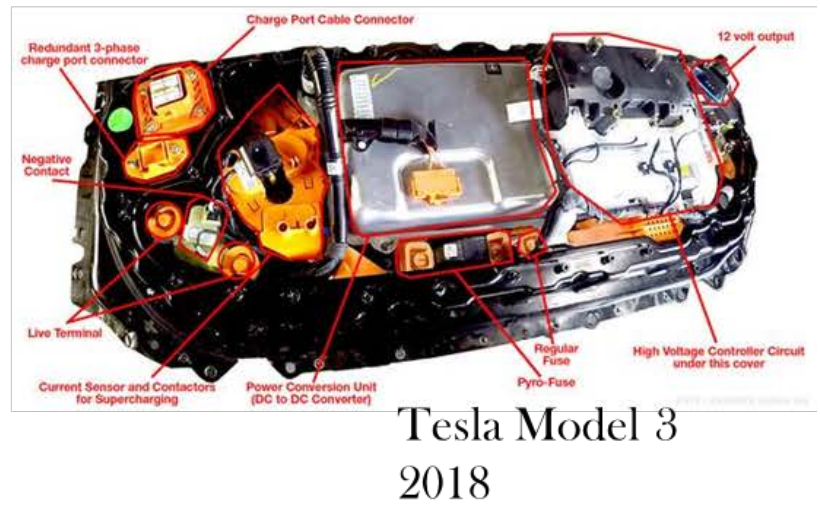




\section{Conventional Approach}

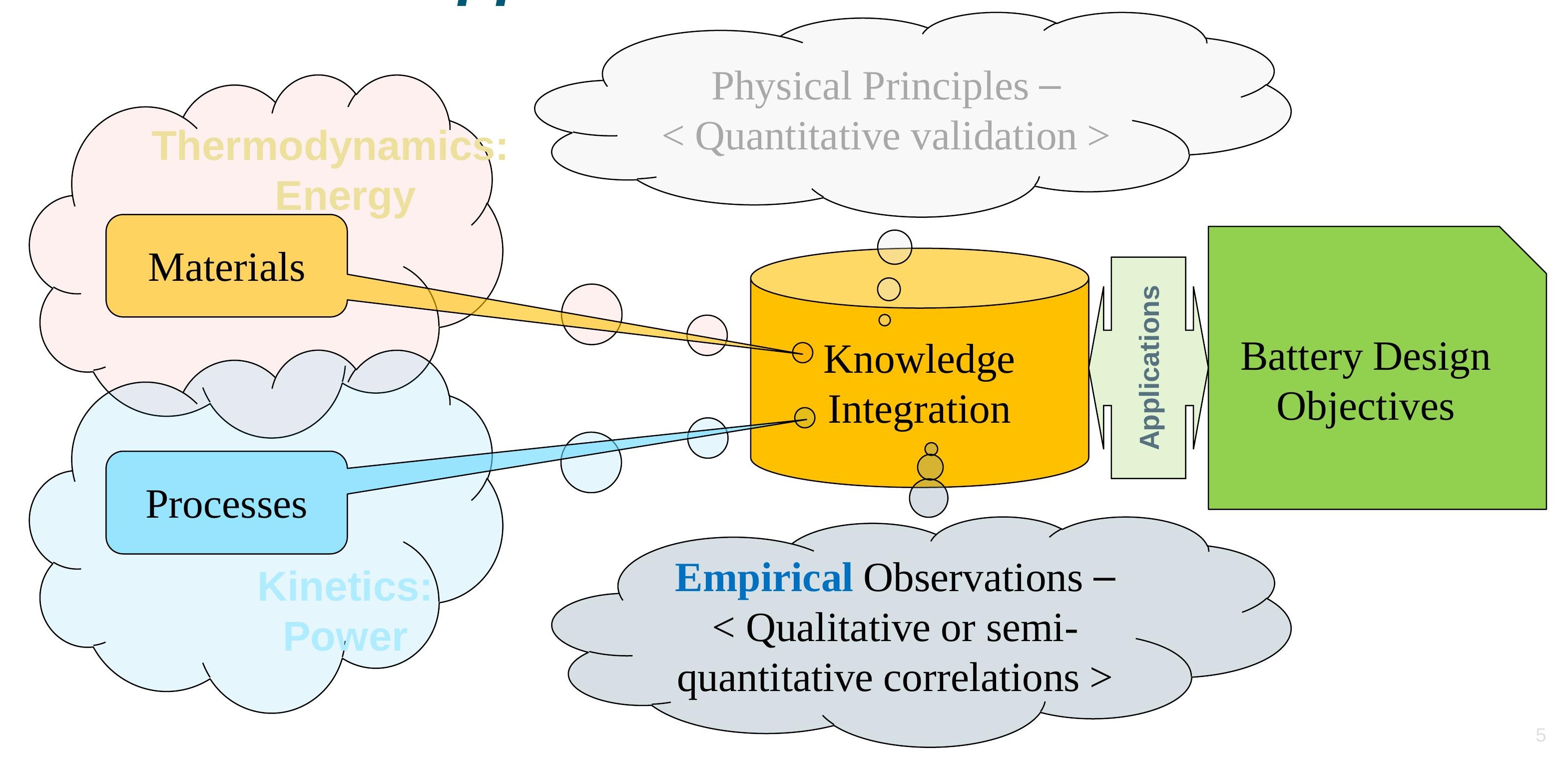




\section{Battery Failure Analysis to Life Prediction}

\section{Thermodynamic Attributes:}
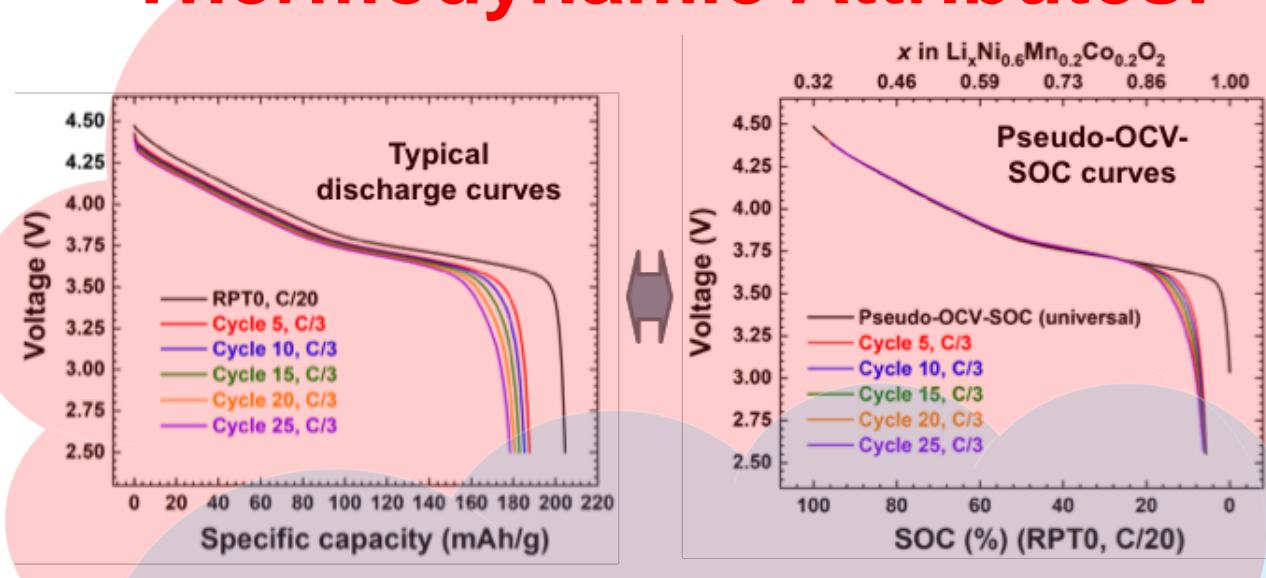

Experimental Conditions
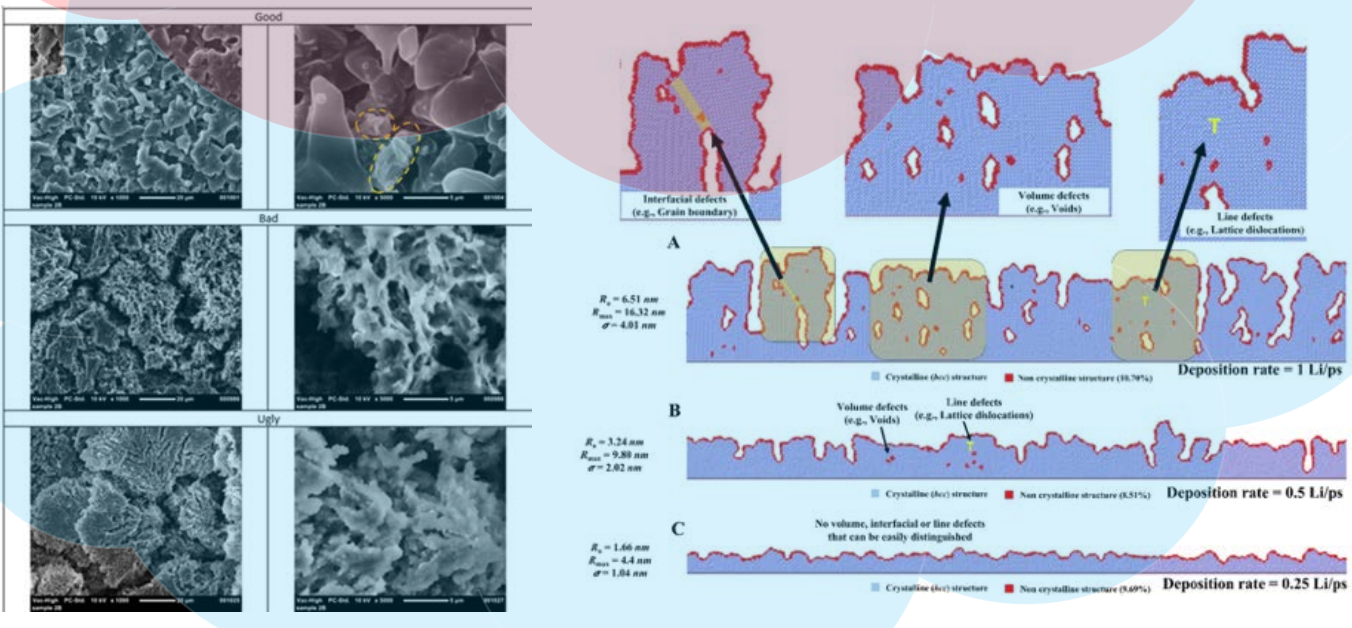

Seposition rate $=0.25 \mathrm{Lips}$

Kinetic Attributes:

Physical Principles -

$<$ Quantitative validation >

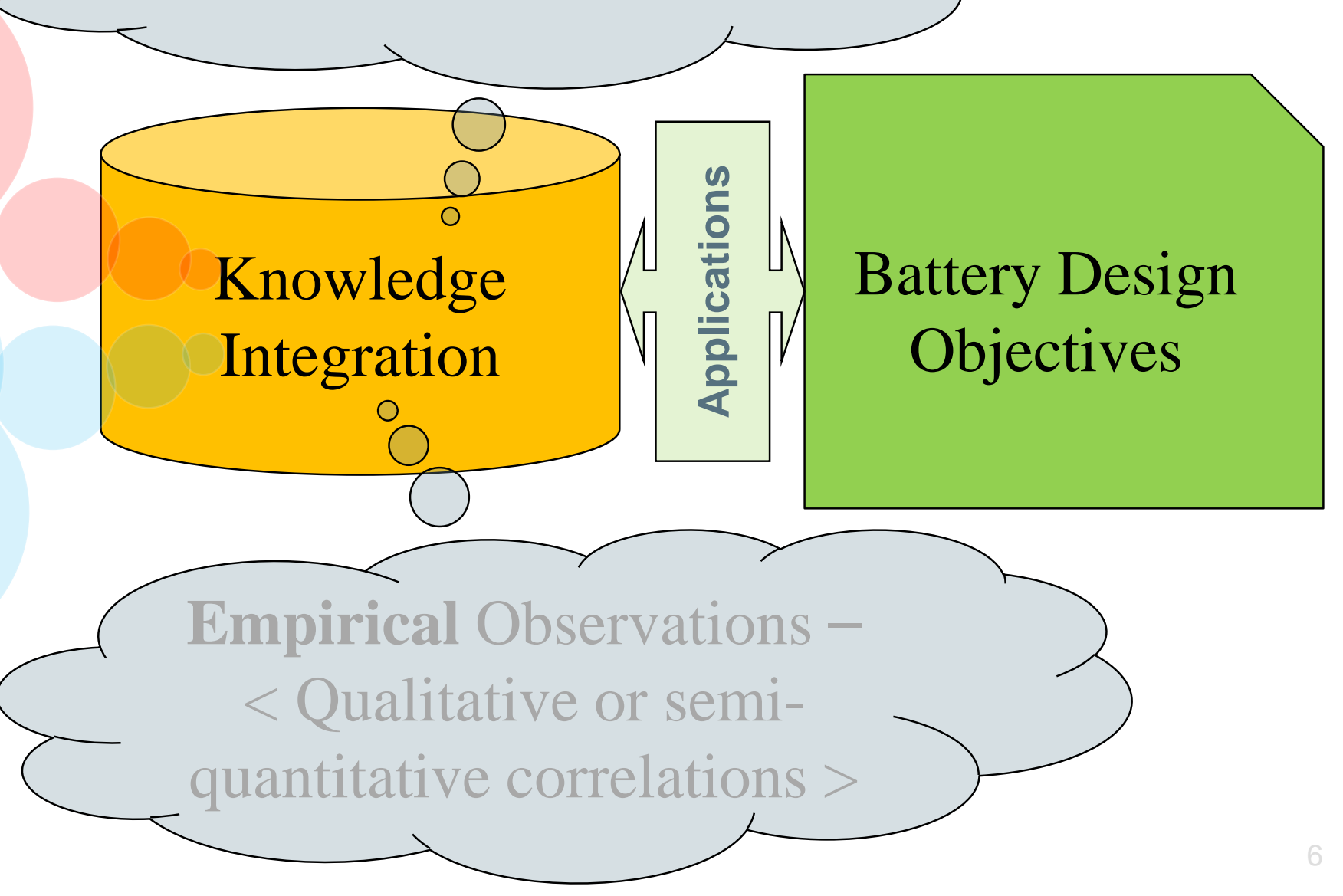




\section{Li Stripping \& Deposition - A Perspective}

- Challenging issues for rechargeable Li batteries with high-energy density and higher cycle life

Dendrite

- Fundamental mechanisms unclear

- Boundary condition is difficult to define

Localized Effects

- Uncontrollable experimental parameters
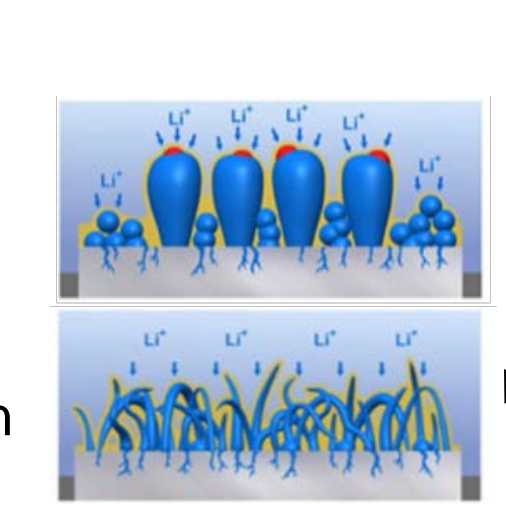

Layla, et al. Scientific reports 6 (2016)

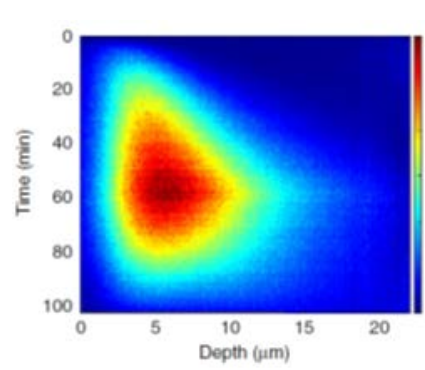

Depth (um) Shasha, et al. Nature communications9.1 (2018): 2152
A dense Li deposition is needed

Li deposition

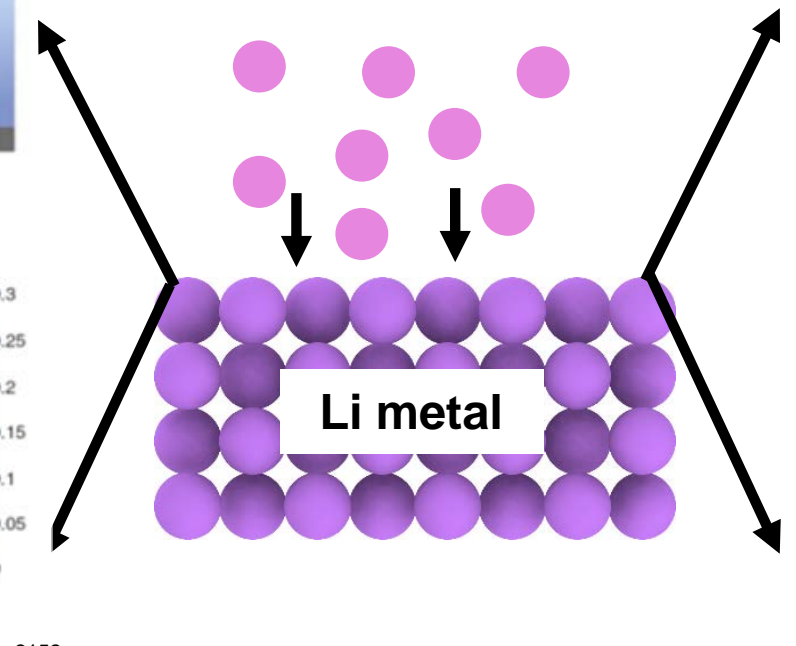

Solid Electrolyte Interphase

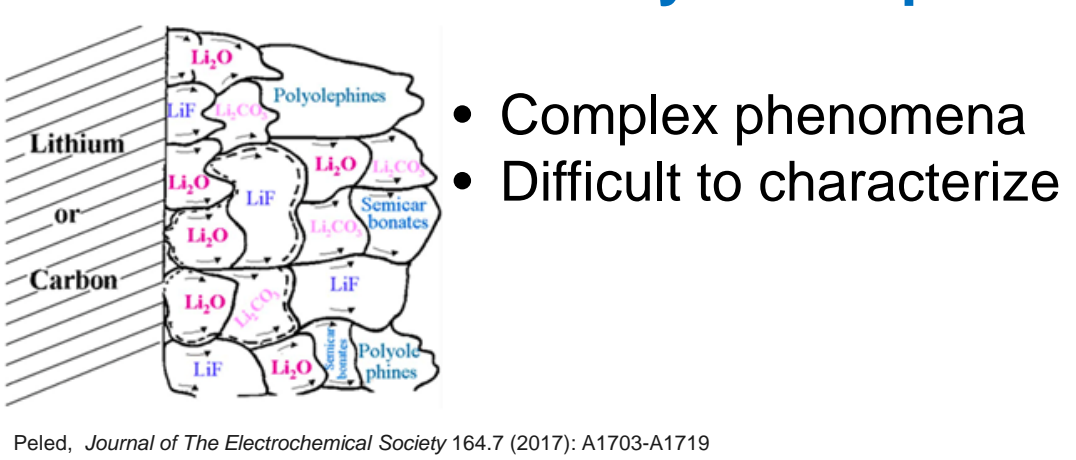

Morphology \& Porosity

- Variability in morphology

- Undesirable effects 


\section{Cryo-TEM Observations on Li Deposition}
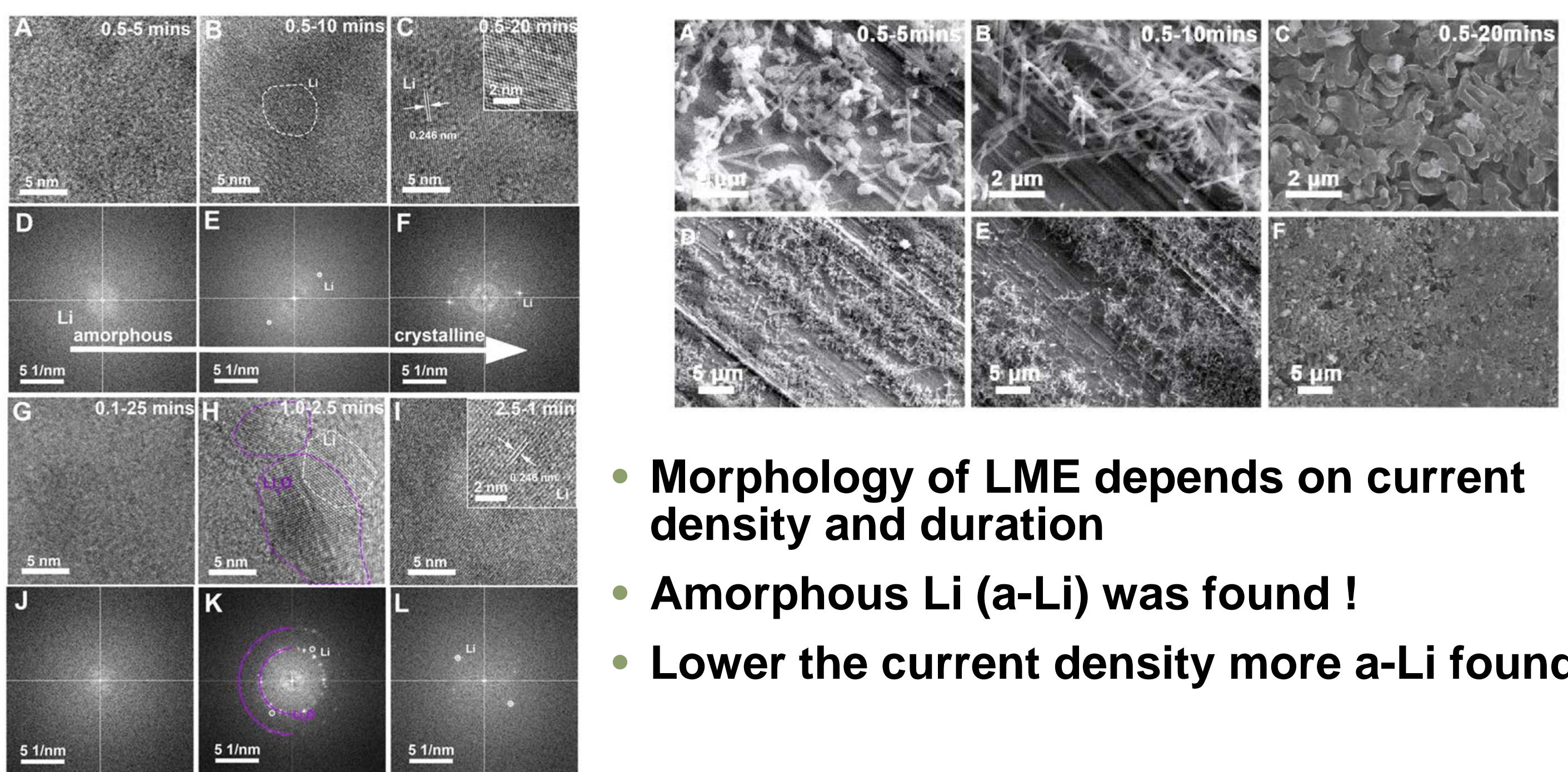

- Morphology of LME depends on current density and duration

- Amorphous Li (a-Li) was found !

- Lower the current density more a-Li found ! 


\section{Simulation - Nucleation}

Understanding of Reaction Kinetics via Reactive

A

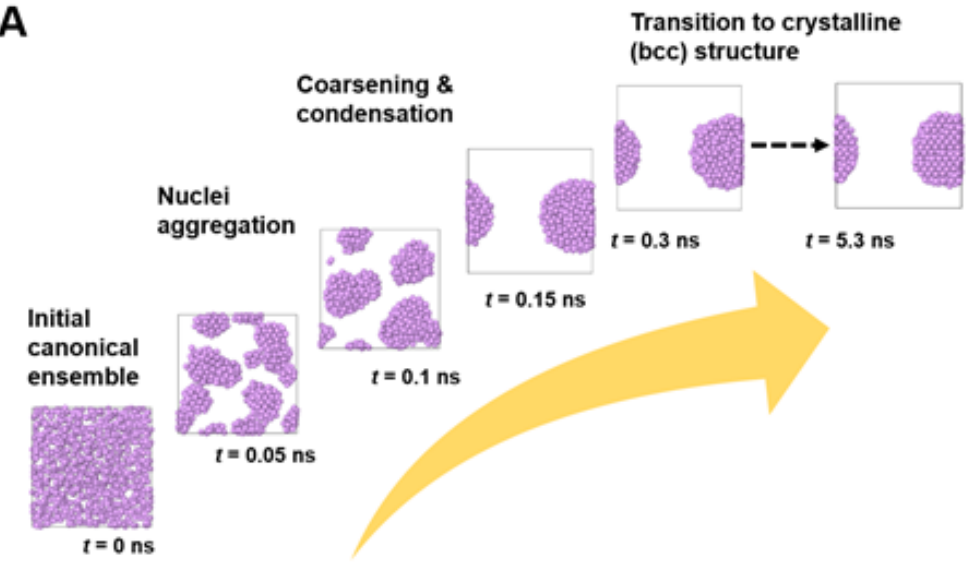

B

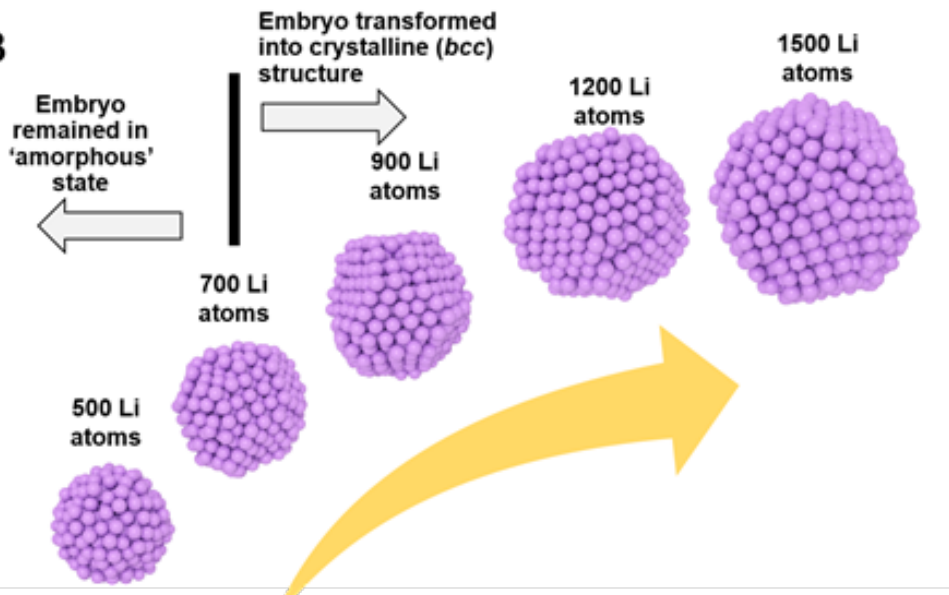

C

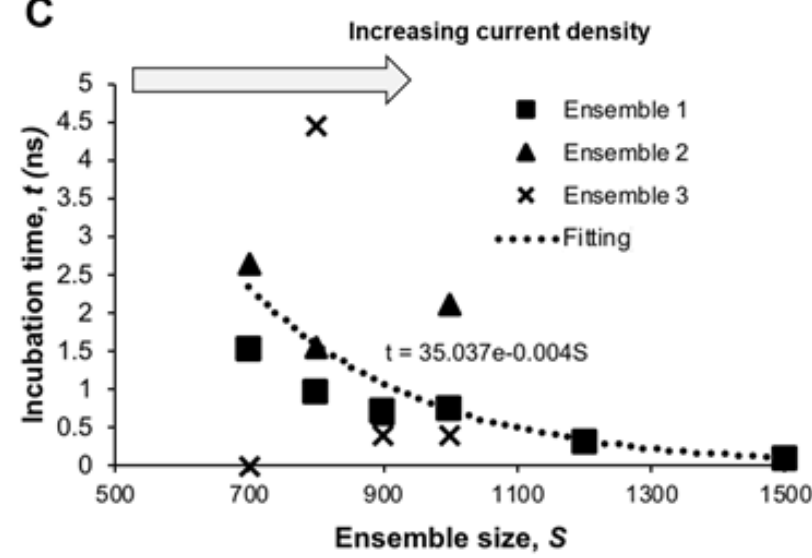

D

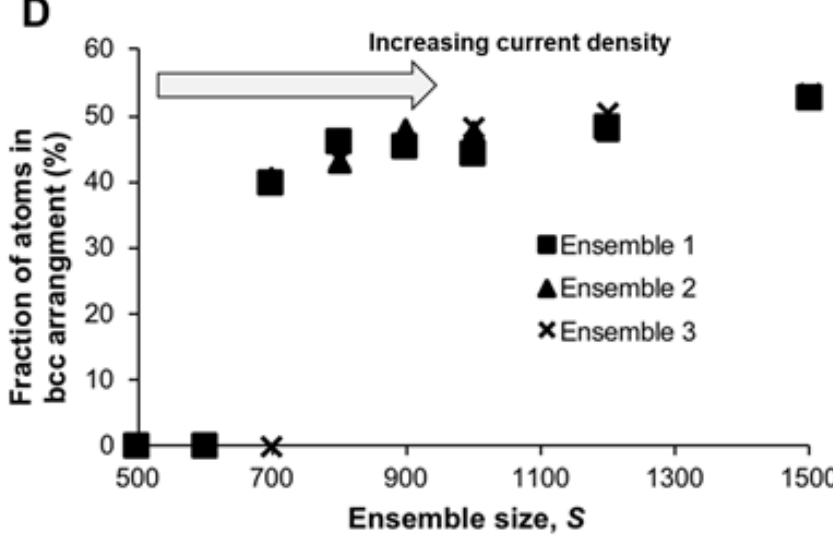

The r-MD simulation suggests:

- Reaction kinetics of nucleation is sensitive to Li embryo size, which is related to current density and duration

- Below a threshold size the Li deposit is an aggregate of $\mathrm{Li}$ in a disordered state amorphous phase or a-Li

- There is an amorphouscrystalline (a-Li to c-Li) transition and incubation

- The threshold size is $\mathbf{2 - 3} \mathbf{n m}$ 


\section{Temporal Evolution of Bulk Microstructure}

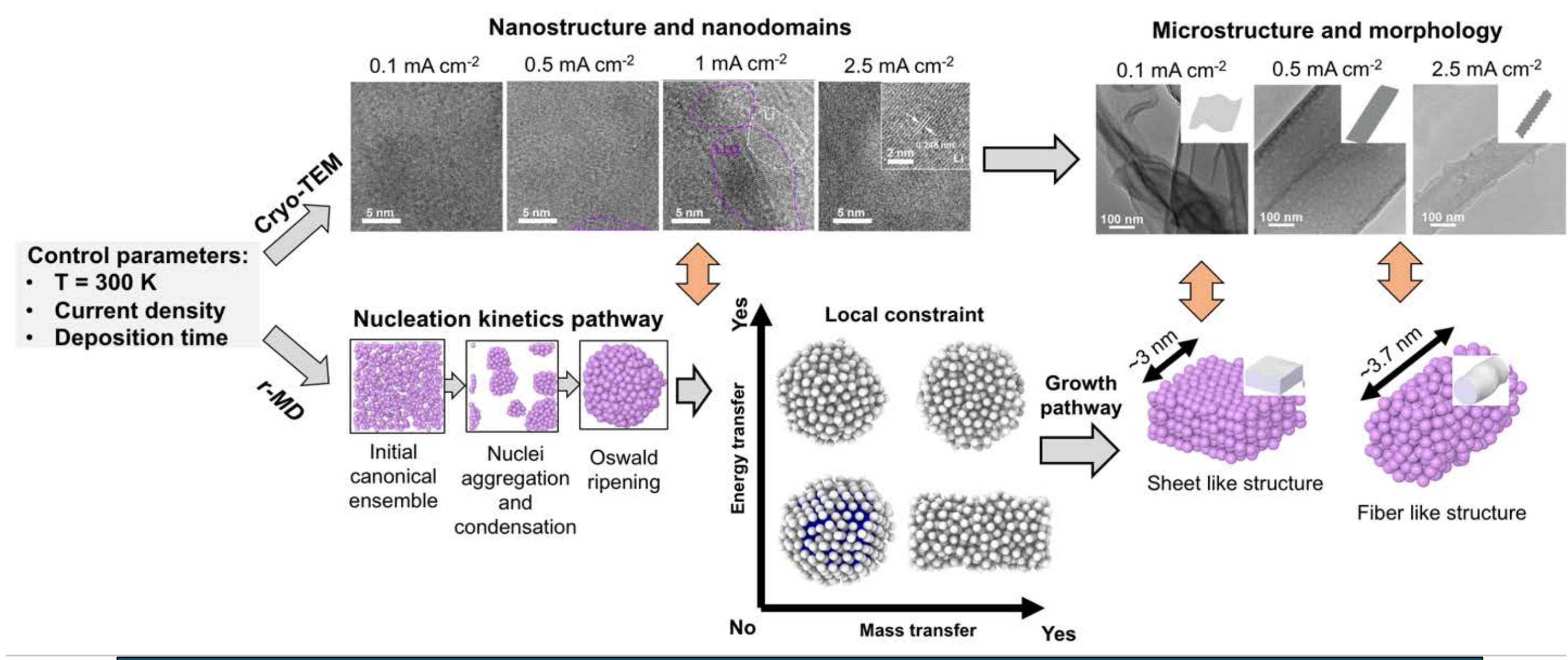

A systematic understanding can enable the identification of kinetic pathways that affects cycle life 


\section{Understanding of Reaction Kinetics via Reactive MD Simulation - Growth}

- Surface morphology and bulk properties

Li deposition rate significantly affects the surface and bulk lithium characteristics 


\section{Rate Dependent Surface Morphology and Bulk Properties}

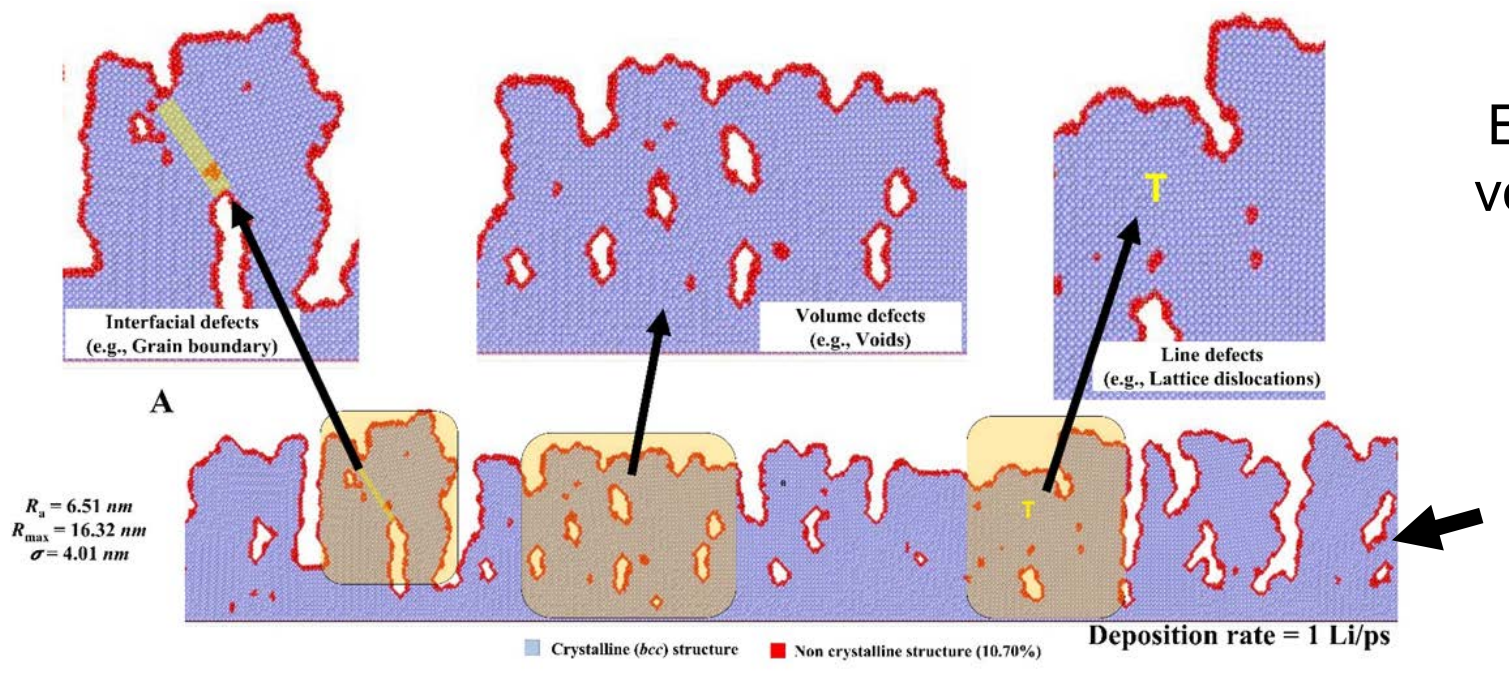

Evolution of interfacial, volume and line defects

High deposition rate

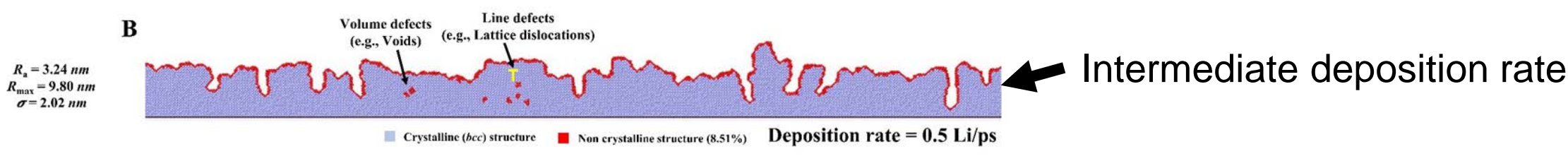
C 


\section{Multi-Scale Fidelity and Reality}

-What governs this multi-scale phenomena is kinetics and the associated energy-transfer process-not thermodynamics.

Using Li metal electrode (LME) as a case study

Micro-scale Meso-scale Macro-scale Nano-scale

Nanostructure and nanodomains

Microstructure and morphology

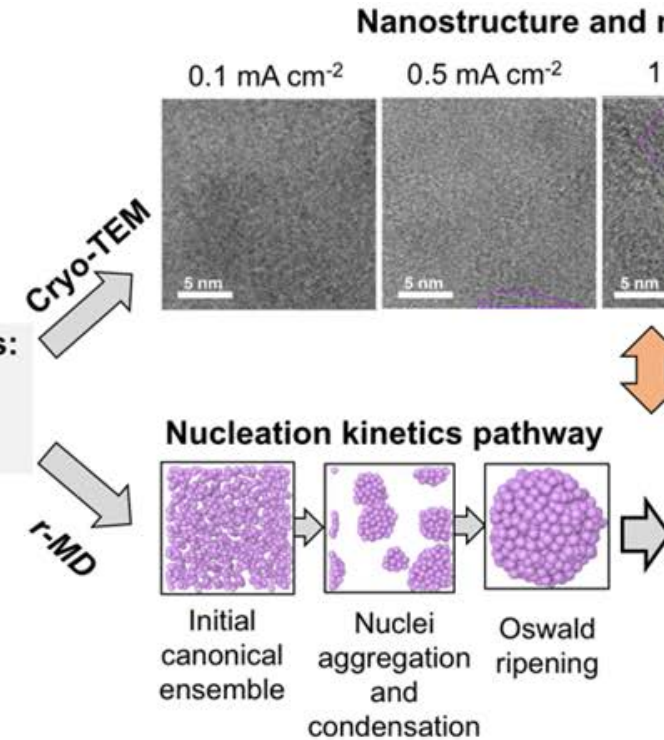

$1 \mathrm{~mA} \mathrm{~cm}^{-2} \quad 2.5 \mathrm{~mA} \mathrm{~cm}^{-2}$
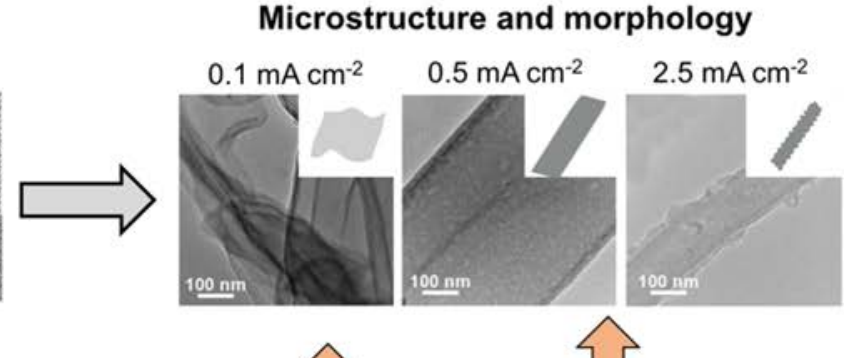

- $\mathrm{T}=300 \mathrm{~K}$

Current density

Deposition time
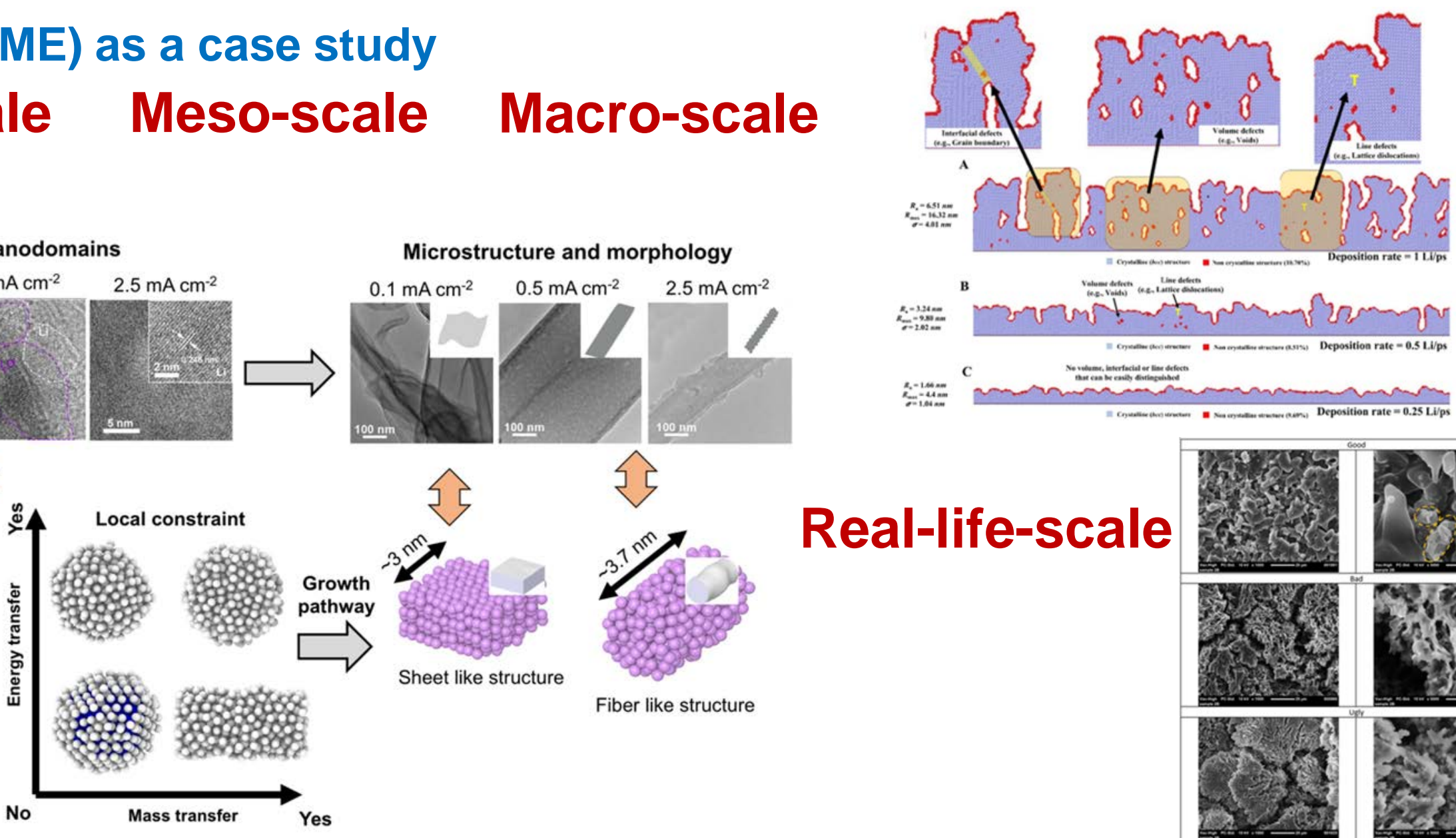

s.t.-.

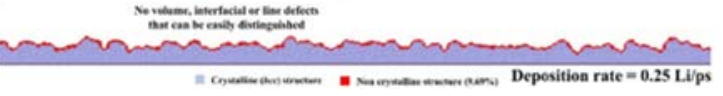

Real-life-scale
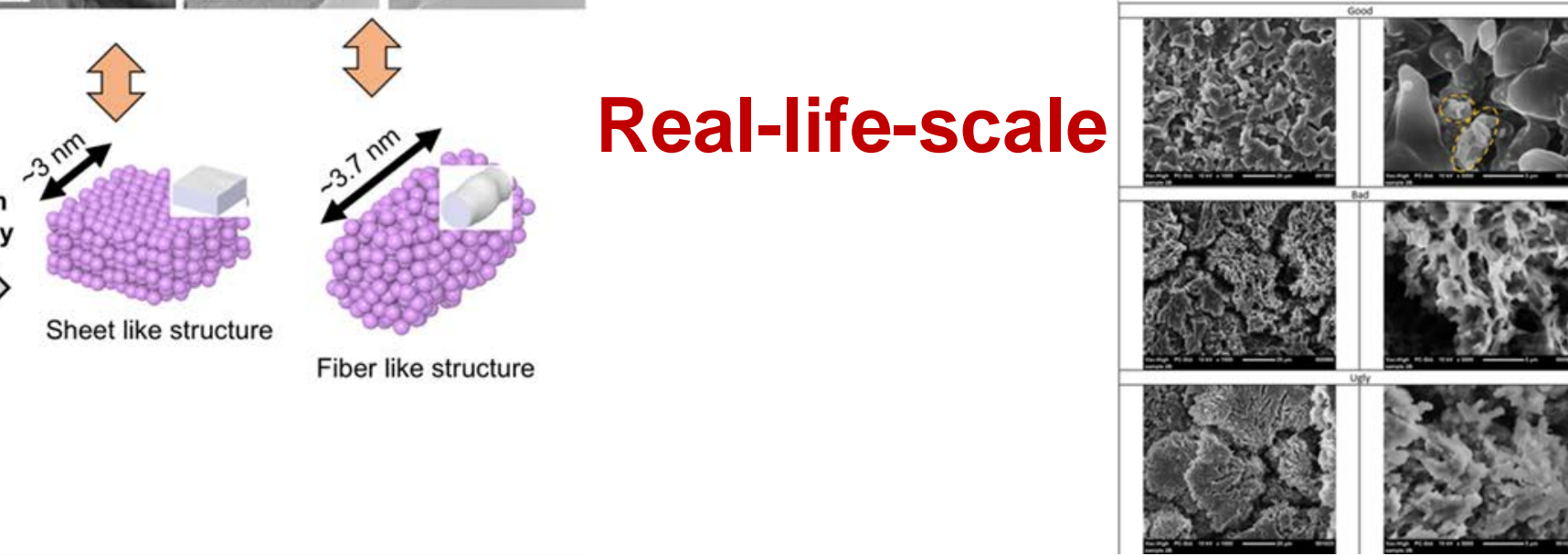

Atomistic 


\section{Cycle Life in Li || NMC Cells}

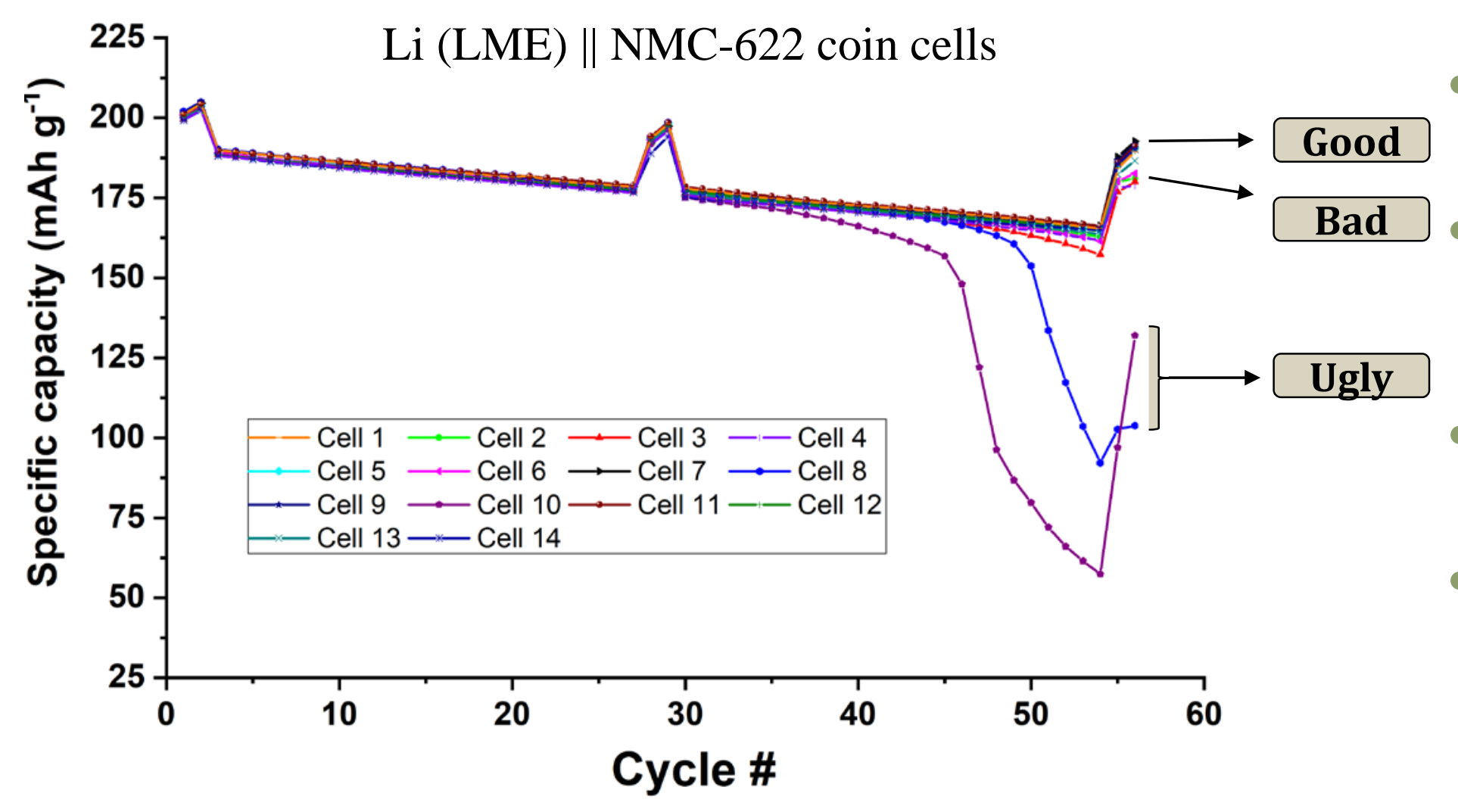

- Consistency in 14 cells offers an excellent basis for eCAD

- Complete life cycle revealed from Good to Bad and Ugly

Full analysis on failure mechanism to identify every single attribute to capacity fade

- Quantitative results for all capacity fade attributes

- Uncover and quantify Loss of Li Inventory (LLI) for charge and discharge regime, respectively, which does not appear in charge retention measurements

- Life prediction for individual cell 


\section{Cell Qualification vs. Statistical Analysis}
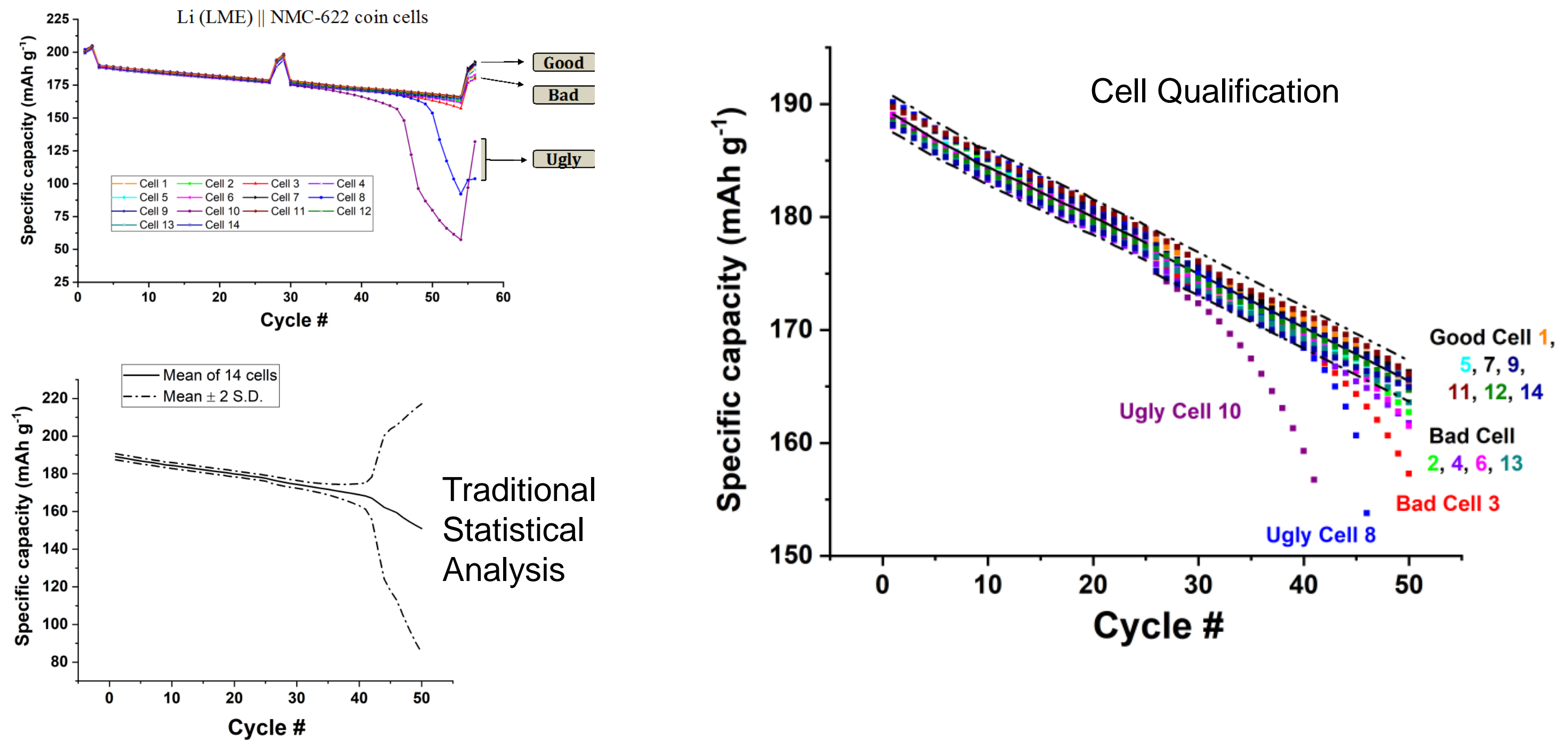


\section{State of Charge (SOC)-based Performance Analysis}

- Remove bias from experimental conditions to reveal true SOC correspondence - Separate thermodynamic and kinetic attributes

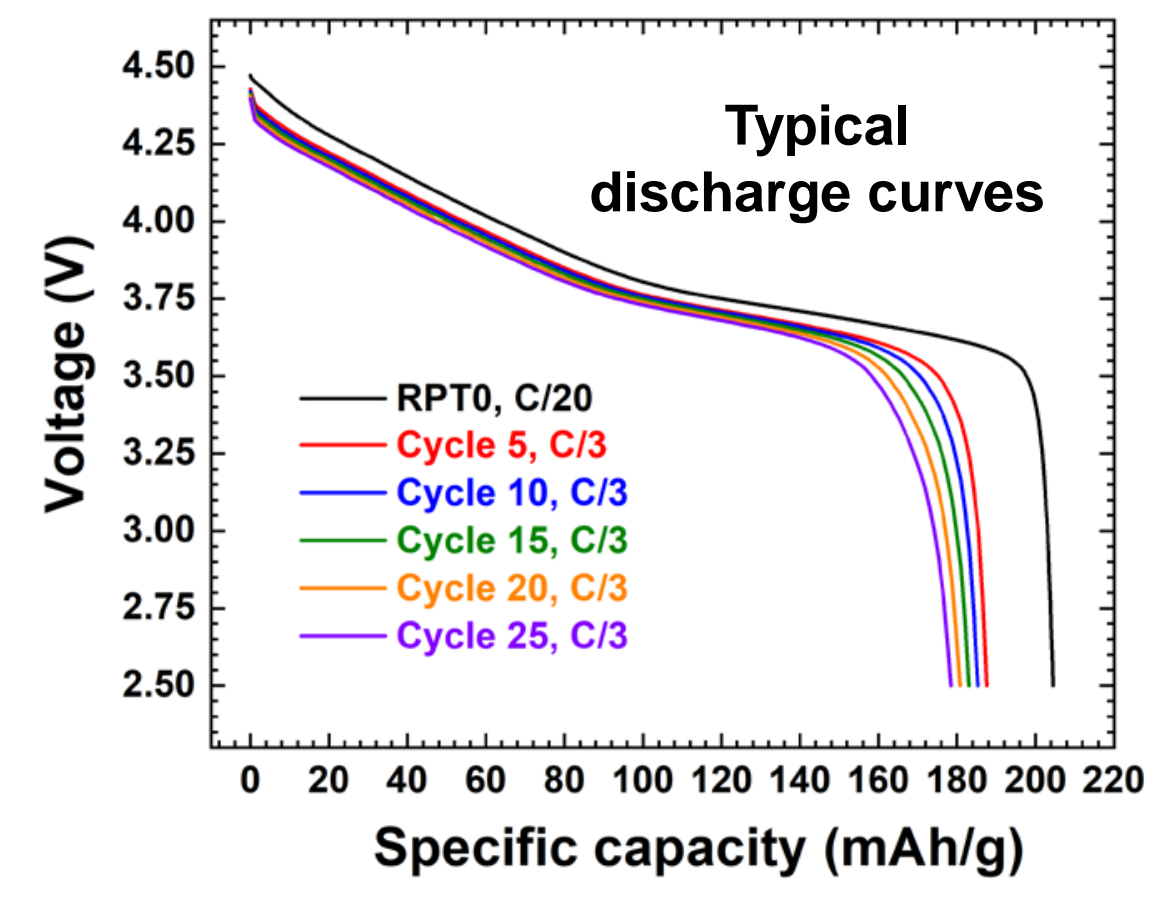

Experimental Conditions

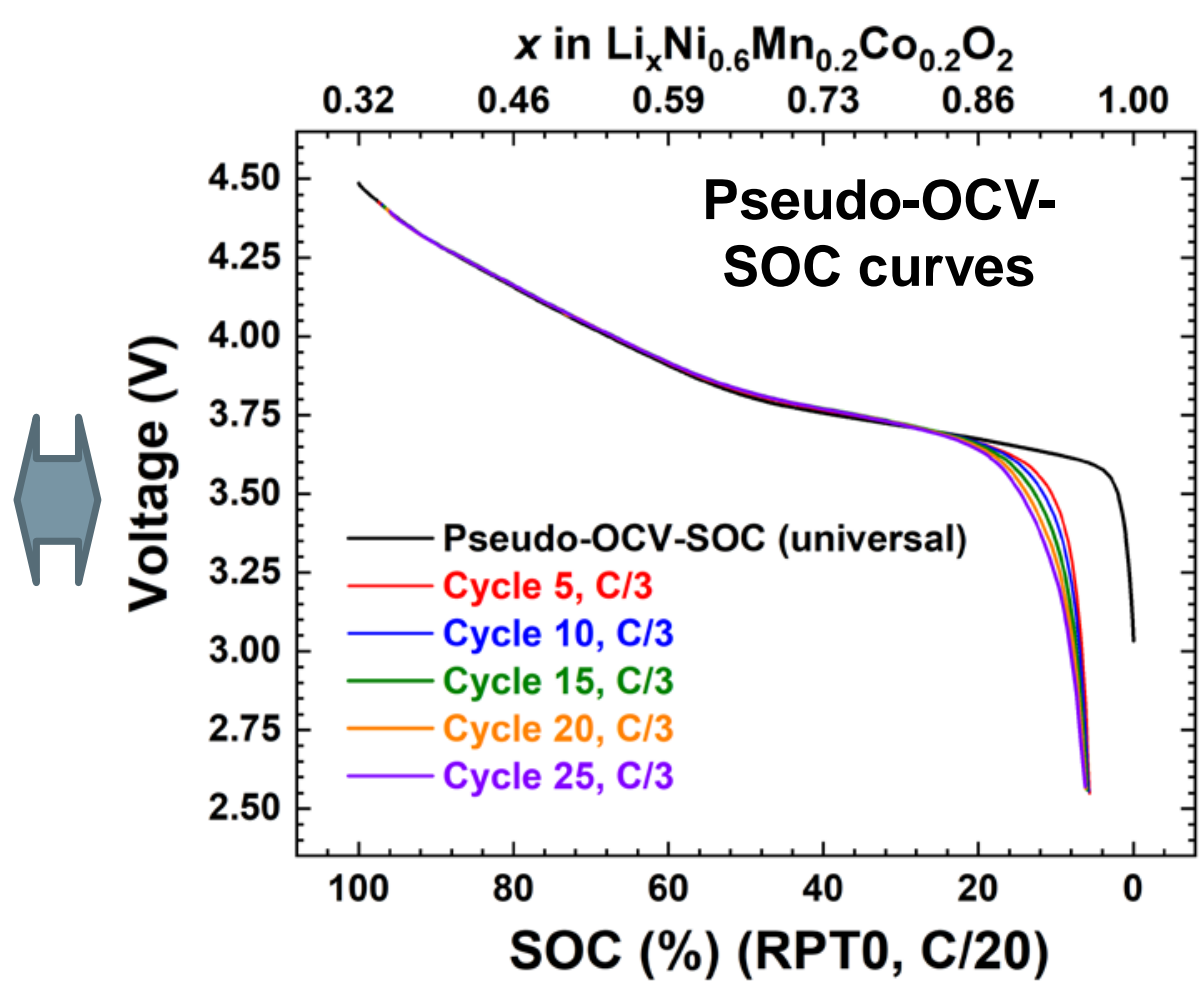

State of the System 


\section{Cycle Life in Li || NMC Cells}

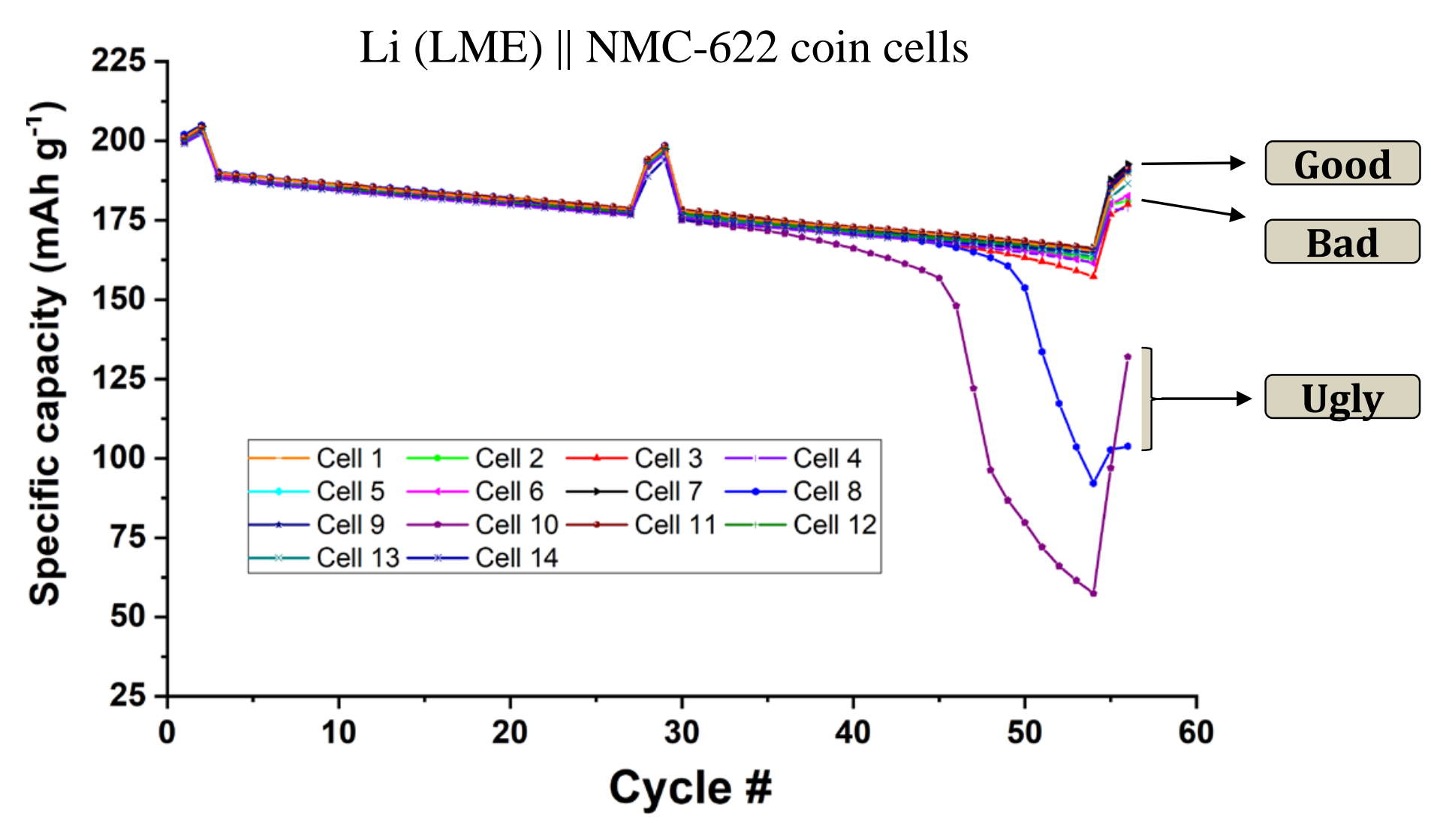

Cycle life sensitively depends on Li inventory

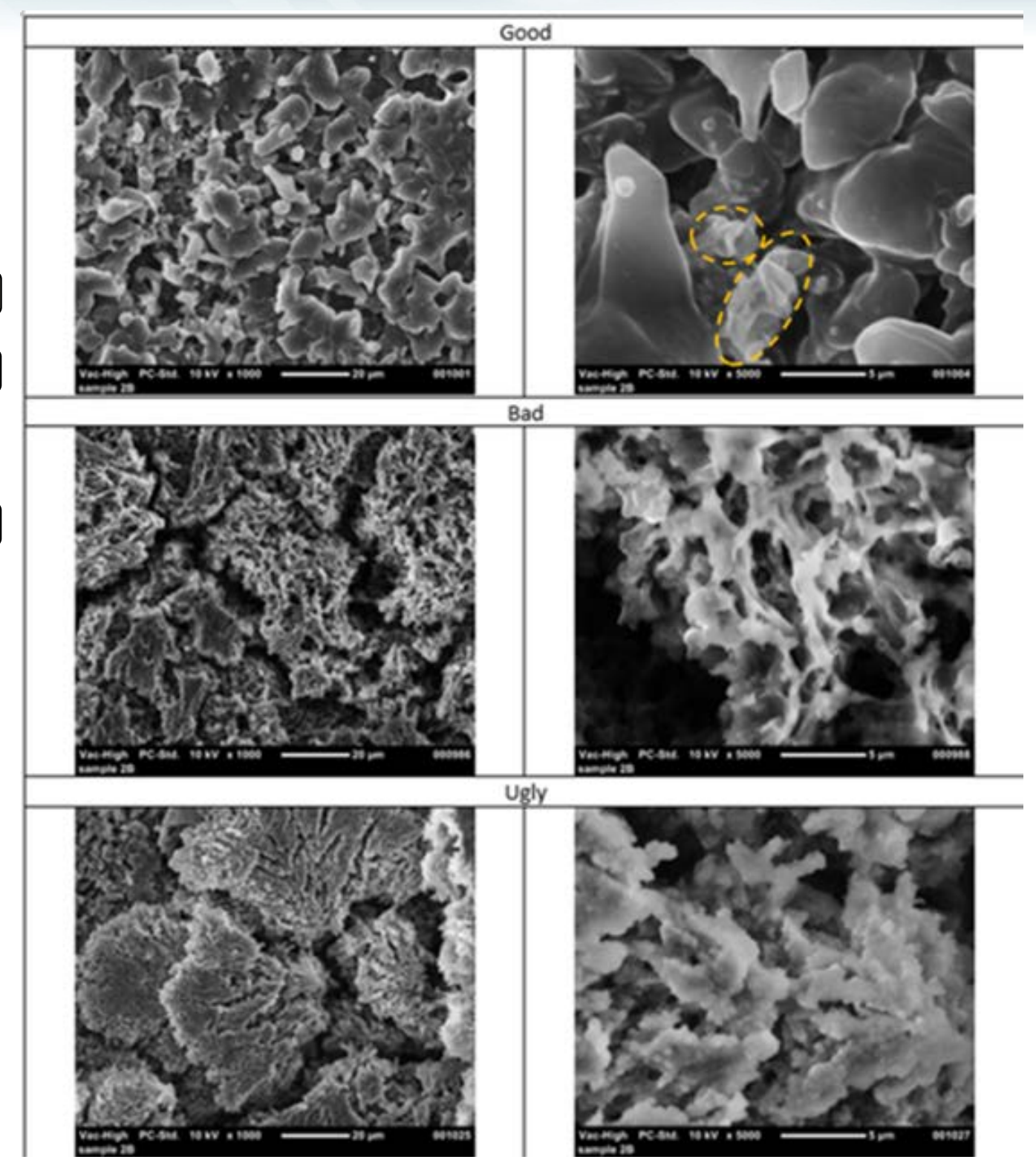




\section{Relate Failure Modes to Li Anode Morphology}
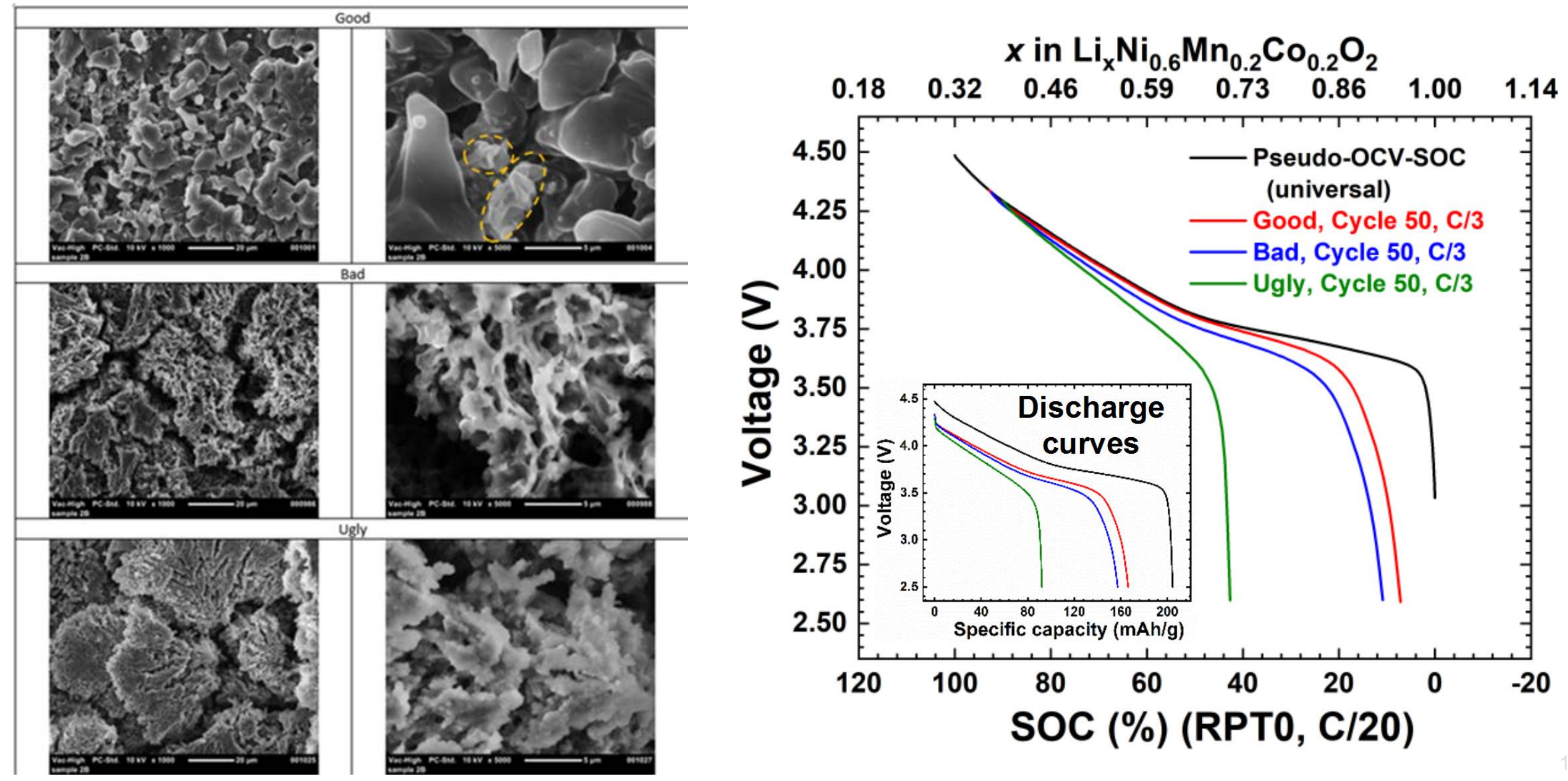


\section{Conclusion}

- Li metal electrode comes a long way to practical applications

- Multi-scale understanding of the kinetics by experiments and model simulations

- Unlock the mystery of Li stripping and deposition with better control of kinetics

\section{To Bob Huggins}

- Happy the $90^{\text {th }}$ B-day !

- Thank you for great mentoring and guidance !!

\section{Acknowledgements}

- Office of Vehicle Technologies of the U.S. Department of Energy in the Advanced Battery Materials Research (BMR) Program (Battery500 Consortium) - David Howell, Tien Duong

- PNNL - Jun Liu, Jason Zhang, Jie Xiao, Wu Xu, Xiaodi Ren

- UC Irvine - Materials Research Institute (IMRI) for the use of Cryo-Electron Microscopy Facility and Kratos XPS 